\title{
(Auto) representaciones en internet de los guardias de seguridad privada peruanos en Irak
}

\section{Giuliana Migliori}

Pontificia Universidad Católica del Perú migliorif.ng@pucp.edu.pe

RESUMEN

Este articulo analiza las autorrepresentaciones en medios sociales (social media) de un grupo de trabajadores peruanos contratados como guardias de seguridad privada en Irak (2005-2012), así como de sus distintas identificaciones referentes a las narrativas hipermediales de internet, sobre la cultura globalizada y normada por la fuerza laboral militar de las compañías transnacionales. Al lado del fuerte arraigo nacionalista, consecuente con la tradición autoritaria y clasista de la sociedad peruana y la realización de su hombría, estas identidades manifiestan una presencia autográfica y épica de las experiencias de migración estacional a través de sus videos y entornos interactivos. Además de fortalecerse el constructo social encarnado por el mercenario, en este tipo de guardia se evidencia una forma de civilidad contemporánea que coadyuva a regular el sistema. Su condición jurídica supuestamente neutra colisiona con una posición empírica de combatiente, lo que da pase a un rol social crítico. En ello cabría la paradoja de un prototipo de sujeto adaptado a la economía de mercado gracias a una guerra y el fortalecimiento de patrones de masculinidad especificos del contexto local.

Palabras clave: autorrepresentación, ciudadanía, seguridad, subjetivación, narrativas digitales. 


\section{Internet (self) representations of the Peruvian Private Security Guards in Iraq}

SUMMARY

This article analyzes the self-representations in social media of a group of Peruvian workers hired as Private Security Guards in Iraq (2005-2012), as well as their different identifications referring to the hypermedia narratives of the Internet, about the globalized culture and regulated by the military workforce of transnational companies. In addition to the strong nationalist roots consistent with the authoritarian and classist tradition of Peruvian society and the realization of their manhood, these identities manifest an autographic and epic presence of seasonal migration experiences through their videos and interactive environments. As well as strengthening the social construct embodied by the mercenary, this this type of guard is a sign of contemporary civility that helps regulate the system. Its legal and supposedly neutral status collides with an empirical position of combatant giving way to a critical social role. In this, the paradox of a prototype of a subject adapted to the market economy would be possible thanks to a war and the strengthening of masculinity patterns specific to the local context.

Keywords: self-representation, citizenship, security, subjectivation, digital narratives. 


\section{INTRODUCCIÓN}

Entre los años 2005 y 2012 se produjo una migración estacional de peruanos a las ciudades de Bagdad y Basora para cubrir alrededor de novecientos puestos de guardias de seguridad contratados por la compañía militar privada de seguridad (CMPS) estadounidense Triple Canopy Co. (Virginia) durante la invasión de Estados Unidos a Irak. La adaptación a las rutinas militares de los Wssp o $B e s f^{1}$ en los campamentos se sostuvo en la interculturalidad por la presencia de otros contratistas latinos, asiáticos y africanos, además de los militares estadounidenses e ingleses, los bandos insurgentes y los pobladores locales, lo que dio origen un proceso alterno de (auto) representaciones, imágenes de resistencia y/o adaptabilidad del cuerpo migratorio que visibilizaron el lado doméstico de las prácticas específicas de socialización de la guerra, como el fenómeno histórico del mercenarismo, entre otras problemáticas de la globalización.

En ese ámbito, los contratistas peruanos que migraron a Irak gozaron del derecho de libre circulación y libre mercado. El escenario económico prometido retaba sus capacidades y experiencias en el campo de la seguridad, pero de otro lado, se abría una zanja discursiva de políticas de reconocimiento y nociones en pugna de ciudadanía, cultura, tradición, territorio, frontera, etcétera, como también de gobernabilidad. El supuesto de libertad e inclusión para estos migrantes tuvo también el revés de la exclusión local por el precedente socioeconómico: la «exclusión-inclusiva» (Paerregaard, 2013, p. 228). Esta condición reluce en el abanico testimonial de las redes sociales que nuclean su protagonismo, con lúcida conciencia de sus roles cívico-militares frente al sistema económico global. Entre tanto, su ser-ciudadanos se avistaba como un proceso cambiante de competencias, adhesiones y luchas de poder cruzadas, empezando por el Estado, hacia dentro y

Distintivos de reclutamiento: Besf(Bagdad, zona verde, americanos), Wssp (Basora, zona roja, ingleses), Irak. 
fuera de todos los márgenes dejados por los desplazamientos, las «mediaciones culturales y tecnológicas, económicas, sociales y políticas» (Fernández Tapia, 2014, p. 97). Los migrantes y los no migrantes, con sus prácticas y en su continua vinculación, forman campos sociales transnacionales que incluyen intercambios materiales y simbólicos mediante los cuales constituyen y mantienen múltiples relaciones que ligan los diversos polos de sus existencias a través de las movilidades y las interconexiones (Bela-Feldman, 2011) .

El guardia de seguridad se autorrepresenta en los entornos online bajo una acción imaginativa difusa ${ }^{3}$, a la vez que suscrita a una militarización progresiva de la sociedad y la cultura; una militarización del espacio traducida en el paradigma de la seguridad privada que ha trastocado la vida doméstica y simbólica de las relaciones sociales y la noción de lo público y lo privado: el sujeto militar, soldado-ciudadano (patriota, nacionalista, etcétera) se transforma en soldado del mundo (profesional, experto) y se subvierten los roles de control interno/externo con la policía (Owen, 2008, pp. 977-990) ${ }^{4}$. En esta polivalencia de sentido, el guardia de seguridad engarza con la figura del mercenario, ambos adaptados a la economía de mercado. Y, en el caso de estudio, a relaciones contractuales asimétricas consecuentes con la tradición autoritaria y clasista de la sociedad peruana. Las identificaciones resultantes de la adaptabilidad socioeconómica conforman el soporte simbólico de los sujetos para subsistir como ciudadanos del mundo.

Por consiguiente, el artículo pretende delimitar la imagen social conformada por los derechos económicos, culturales, tecnológicos, representacionales, etcétera de los guardias de seguridad, mediante categorías de análisis visuales basadas en variables epistémicas de ciudadanía: «ciudadanía reconocida (la legal, nominal), ciudadanía percibida (la identitaria-simbólica) y la ciudadanía vivida (ejercicio y disfrute de derechos y realización de deberes y compromisos cívicos), a través de las que se realiza la ciudadanía a nivel local, nacional y transnacional» (Fernández Tapia, 2014, p. 97). Dado que los derechos humanos de estos actores sociales — concebidos desde el ámbito puro del derecho- pueden ser insuficientes para el reconocimiento incluso nominal de las ciudadanías transnacionales. Prevalece

\footnotetext{
Ver: Feldman-Bianco, Rivera, Stefoni, Marta Villa (comp.), 2011, Introducción.

Ver en: http://www.taringa.net/posts/videos/12397395/Peruanos-son-Atacados-con-Morterosen-Irak-18.html (actualización, octubre, 2017).

4 «La idea de que la seguridad y la inseguridad son hoy experimentadas y practicadas en formas que fusionan lo interno y externo, lo público y lo privado, es una característica importante de la literatura reciente sobre los cambios del carácter de la guerra y la seguridad» (Owen, 2008, pp. 977-990, traducción del autor). Sobre la inclusión sistemática de civiles en los conflictos para atacar la raíz sociocultural de las sociedades, ver Golinger, 2016.
} 
una lógica cultural, donde la subjetividad de los grupos humanos altera el balance de las razones autoritativas (MacCormick, 2008, pp. 65-78)5.

A simple vista, estos videos afrontan la cuestión de la vida bajo la mirada del poder político y los valores que rigen un sistema social al encarar nuevamente una guerra, (Foucault, 1976, p. 217; 2004, p. 218). El guardia de seguridad transfiere su derecho de vida y muerte a un rol potencial de soldado por la sujeción de un contrato (un poder) legitimado en la experiencia y no por cláusula nominal del mismo documento, donde se le confiere un estatus neutro. Si, como señala MacCormick, «un tipo de razón para actuar o no actuar de determinada forma deriva de lo que ese actuar o no actuar ocasionará», permanecer neutral no dependerá únicamente de principios jurídicos puros, sino del instinto de supervivencia, ya que de estos hilos económicos se deja entrever otra esfera de identificaciones donde se ejercita la hombría en favor de la economía doméstica y en estrecha relación con una forma de dominación epistémica culturalmente naturalizada, es decir, un tipo de dependencia estructural.

Esto se deduce por los enunciados moralizantes relacionados con el valor, la fuerza, la lealtad, el futuro, la familia, la demostración de habilidades, la educación, la raza, la clase, la inteligencia, la viveza, el patriotismo, la explotación, los sentimientos, etcétera. Siguiendo la teoría cognitiva, la ola migratoria de este trabajo subalterno transmutaría constantemente y tendría «la capacidad de configurar el flujo de sus individualidades que lo componen» (Mejía Navarrete, 2015, pp. 292-296). En consecuencia, el acercamiento al tramado de narrativas digitales ha suscitado una lectura hipertextual crítica de las autorrepresentaciones y una interpretación antropológica multilineal (Landow, 1995, pp. 13-49). Al intentar deshilvanar el tejido nominal estático de las ciudadanías, se extienden más los estereotipos, pero se expone la autopercepción de estas personas como sujetos del mundo liberados por los mismos procesos sociales excluyentes.

\section{METODOLOGÍA DE CAMPO}

El estudio se llevó a cabo online entre 2011 y 2014 y se contactó a tres ex guardias, de los cuales se entrevistó personalmente a dos. El productor del documental America's 33 dollar mercenaries, Fernando Lucena (2013), sobre el mismo caso de los peruanos en Irak también colaboró con el estudio. A partir de

5 MacCormick, Neil (2010). Argumentación e interpretación en el derecho. DOXA, Cuadernos de Filosofía del Derecho, 33: «... el perenne problema de la situación humana es la disputabilidad interpersonal de los valores y principios que deberían guiarnos». 
estas interacciones se desglosó nueva data, así como de procesos intermitentes de creación visual por los guardias. Se ha procurado remarcar voces colectivas antes que individuales, manteniendo los anonimatos y seleccionando las imágenes reproducidas, no necesariamente por las controversias mediáticas ni por falta de consentimiento, sino por énfasis en el fenómeno mismo y en las imágenes. El desafío del campo heterogéneo abre múltiples entradas al problema, y por eso uno de los factores básicos para vertebrar el estudio fue el hecho de constatar que las autorrepresentaciones alojadas en YouTube eran valoradas por estos con inherencia a sus demás prácticas cotidianas, su conciencia de ciudadanía y sus planes de desarrollo personal en un mundo globalizado.

Aunque la motivación del estudio partió por incidir en la subjetivación del valor documental de las imágenes referidas a este caso, los avances lo orientaron gradualmente hacia una regulación eficaz de la metodología, en congruencia con el valor testimonial de los videos y otros elementos de la plataforma. En la fase exploratoria, la inmersión de campo implicó una suerte de alfabetización digital personal e ideación de recursos de elicitación y comunicación con los actores sociales. La manipulación artística de los archivos dejó entrever nuevas yuxtaposiciones al problema a través de un video-elicitación que se colgó temporalmente en YouTube, pero sin resultados relevantes. En cambio, desde Facebook se pudo observar que la suficiencia testimonial de las personas, imágenes y redes sociales acuñaba ya un proceso abierto e intercultural de autorrepresentación consustancial a su configuración dentro del social media. Al conjunto medial analizado se suman los foros, algunos canales de YouTube, sites de prensa y blogs.

\section{SOBRE LA (RE)CONSTRUCCIÓN DE CIUDADANÍAS VIRTUALES Y PLEGABLES POR LA PRODUCCIÓN INCESANTE DE DATA EN CONTEXTOS INTERACTIVOS}

Para poner énfasis en la locación principal de las autorrepresentaciones de los guardias de seguridad, se dispuso un orden de categorías sociales, visuales e interactivas de doble articulación: la semántica específica y móvil de las mediaciones virtuales, como el broadcasting personal (por ejemplo, YouTube, Facebook), más los aspectos de la recepción y socialización online-offline, reveladores críticos de un hecho social maleable en imágenes de inclusión/exclusión, subalternidades, intersubjetividades, glocalizaciones, la fusión de lo público y lo privado, etcétera ${ }^{6}$.

6 La fusión gradual del orden público y privado generan la proliferación de CMPS a partir de la década de 1990. Laborie-Iglesias analiza las causas: expansión tecnológica / eficiencia económica 
Por esta razón, la recolección e interpretación sincrónica de data implicó una lectura ramificada, concéntrica e impredecible del hecho, similar a la decodificación de una narrativa digital ${ }^{7}$. Vale decir, una construcción de la información supeditada a las condiciones de interactividad donde «la historia será fruto de las decisiones de la persona receptora ${ }^{8}$. De ese modo, aunque los videos pudiesen evidenciar la transmisión histórica de una fuerza laboral peruana en el extranjero, las aseveraciones tajantes quedan descartadas, así como la idea de que en ese entorno existiría una pragmática consensuada.

Antes bien, siguiendo el cuestionamiento del presupuesto de utilidad social para las prácticas de youtubing entre «un individualismo metodológico y un holismo» $(\mathrm{Gu}, 2014$, p. 2), se pudo reflexionar sobre este fenómeno migratorio desde la óptica del individuo y/o grupo: «El uso que la gente hace de YouTube puede significar lo que la misma práctica social interactiva del youtubing sea en el momento característico de subir videos y compartir sus actividades de la vida diaria» $\left(\mathrm{Gu}, 2014\right.$, p. 2) ${ }^{9}$. En esa medida, puede que haya quedado clara la prevalencia del aspecto motivacional inherente al youtubing, para que los guardias de seguridad hayan generado y transmitido este tipo de media. Sin embargo, todavía queda para el estudio conocer muchos más aspectos del consumo de estas imágenes y su relación con una visualidad mayor.

Fuera de estas razones ancladas en el sujeto-guardia, se revisó literatura acerca del contexto sociohistórico de las Compañías Militares Privadas de Seguridad (CMPS), sus marcos legales y la cuestión de los derechos humanos, por los efectos en la gobernabilidad y organización del trabajo local/translocal. Entre los diversos instrumentos internacionales regulatorios de violencia o violación de los derechos humanos, la Convención Internacional contra el reclutamiento, utilización, financiación y entrenamiento de mercenarios es específica al reconocer como hecho violatorio de los derechos humanos el fomento de la categoría social conocida como mercenarismo ${ }^{10}$.

/ reducción de efectivos / globalización / conflictos étnicos y regionales. Ver en op. cit.: LaborieIglesias (2012, pp. 25-26).

7 En este punto, conviene diferenciar mínimamente las acepciones de narratividad de la esfera exclusivamente literaria, para introducirnos en un tipo de narratividad performativa, donde las enunciaciones o expresiones permiten acciones. Véase: Echeverri Ortiz, 2011.

8 En este caso, la recepción o lectura de quien investiga. Ver en: http://narrativa-digital.blogspot. pe/2011/04/caracteristicas-de-la-narrativa-digital.html

9 Traducción personal.

10 El gobierno peruano se adhirió a esta convención contra el reclutamiento de mercenarios en el segundo gobierno de Alan García. En http://peru21.pe/noticia/79646/gobierno-peruano-seadhiere-convencion-contra-reclutamiento-mercenarios (acceso: 2014 y 2017). 
Los problemas de reconocimiento que surten de dicha matriz de prácticas en seguridad privada estarían estrechamente relacionados con esa problemática. Empero, si correspondiera para el caso peruano quebrar el eufemismo de guardias de seguridad por mercenarios y abrir el debate ético, valdría aclarar antes que la mayoría de contratados no tenía filiación militar, policial o capacitación en seguridad $^{11}$, necesarias para sortear el terreno especulativo de las identidades según las normas. No obstante, el estudio prioriza al sujeto militar como la categoría social de identificación para este grupo de migrantes, debido a que el destino laboral fue una guerra y los contratos exigían habilidades implícitas en dicho rol, además de los valores nacionalistas, entre otros signos de poder, control y fuerza. De acuerdo con la información, la participación del Ejército peruano fue predecible por la privatización y globalización gradual de prácticas que antes estuvieron supeditadas al orden público. Las CMPS abarcan empresas privadas de seguridad y empresas de servicios militares, operando dentro del mismo contexto - la guerra - y, enfrentando problemáticas comunes. Como la identidad de los sujetos contratados se vio cuestionada por la semejanza con los casos de mercenarismo que atraviesan las CMPS y por la salvaguarda de intereses de la empresa privada de la guerra o de la comunidad internacional, se aplicó otra tipificación de roles sociales: mercenario / trabajador-neoliberal, guardia-soldado / soldado-ciudadano / héroe / militar / civil.

Ante las violaciones recurrentes a los derechos humanos, como se dio en Blackwater $^{12}$, desde el año 2008 han surgido sucesivos convenios internacionales que amplían el umbral ético de los estados ante las CMPS como el Documento de Montreux (Suiza) ${ }^{13}$. Aun así, la regulación integral del mercenarismo dista todavía del debate sobre las problemáticas sociales en procesos migratorios, de

11 Ciertamente, entre los trabajadores hubo ex militares y ex policías, pero según los datos consultados no representan la totalidad: poco más de doscientos. No obstante, según los reportes de prensa, el Ejército peruano tuvo un papel mediador y habilitador de los procesos logísticos de las contrataciones sobre este grupo humano mixto. Ver: En el Ejército se entrenaron peruanos que fueron a Irak, http://www.ipsnoticias.net/2005/10/peru-mercenarios-para-iraq-con-ayuda-del-ejercito/ Ver también: http://larepublica.pe/politica/293244-en-el-ejercito-se-entrenaron-peruanos-quefueron-a-irak (acceso: noviembre de 2017).

12 Ver: Juicio al pasado de Blackwater EE UU sienta en el banquillo a cuatro exagentes por matar a 17 civiles en Irak en 2007 https://elpais.com/internacional/2014/07/02/actualidad/1404329138_563572.html (acceso: noviembre de 2017).

13 Ver: El Documento de Montreux sobre las empresas militares y de seguridad privadas: Actas del Seminario Regional para América Latina. Centro para el Control Democrático de las Fuerzas Armadas de Ginebra (DCAF), a petición del Departamento Federal de Relaciones Exteriores de Suiza, 2011. En el documento se usan las siglas EMPS para estas compañías. La tesis de este 
donde también puede germinar este fenómeno y encarnarse en el guardia de seguridad y/o el trabajador transnacional.

Sin embargo, tanto el valor testimonial de los guardias peruanos como sus autorrepresentaciones han relativizado cualquier discurso oficial o libre que debata la figura del mercenario. El velo político local zanjó el tema de las contrataciones por el lado de la victimización (presunta explotación de agentes extranjeros), sumándose un despliegue de narrativas sensacionalistas ${ }^{14}$. Por ende, se hace comprensible que la figura del mercenario en general haya pervivido en el imaginario colectivo como un arquetipo abstracto, un sujeto sin bandera cuya definición jurídica se confunde con la de combatiente ilega $1^{15}$.

Desde el plano jurídico y representacional (estados, organizaciones internacionales), pasando por las instancias mediáticas y el correlato digital e interactivo de las autorrepresentaciones del sujeto, los procesos de identificación, adaptación, autonomía o arraigo cultural estarían permanentemente resignificándose y yuxtaponiéndose en virtud de la sumatoria de valores que la tradición de los derechos humanos ha concedido como marco fundamental de convivencia democrática: dignidad, libertad, igualdad, etcétera. Es por ello que la política actual exige establecer nexos entre reconocimiento e identidad, puesto que esta última se moldea a causa de — o a falta de - reconocimiento (Taylor, 1993, pp. 53-54).

Fuera del binomio online-offline, hay una condición multifocal del migrante que compromete nuestra propia conciencia de ciudadanía. Su reconocimiento político, al lado de las asociaciones con la vida militar o acaso con el mercenario, cuestionaría sus libertades individuales, donde por gravedad del grupo especificado recae también un sumario de masculinidades. Este hecho, aunque ligado a una idiosincrasia particular, se alinea tácitamente con una marea transcultural de ejercicios de hombría y virilidad. El filtro medial provocaría una subjetivación constante de este suceso, no solo por los videos donde historia y ficción

artículo se apropia de CMPS, según el texto de Armendáriz. Cabe resaltar que las categorías propuestas por el autor discurren sobre la filiación, territorio de operaciones y rol de los estados. Ver: http://peru21.pe/noticia/31579/piden-al-gobierno-informar-sobre-condiciones-vidaperuanos-irak. Ver también: «Usan a peruanos como mercenarios en Irak», entrevista radial con Zenaida Solís: Óscar Andía Cusi, uno de los peruanos que trabajó como guardia de seguridad en Irak, relata las amenazas que recibió al salirse del equipo de mercenarios en Irak. En http:// www.webislam.com/noticias/45671 (acceso: 2014).

15 Para mayor detalle ver: «La privatización de la defensa: compañías militares privadas y mercenarios», Fernando Arnacon, en: http://elordenmundial.com/guerras-conflictos/laprivatizacion-de-la-defensa-companias-militares-privadas-y-mercenarios/ (acceso: 2014). Véase también: «La situación jurídica de los 'combatientes ilegales/no privilegiados'». En https://www.icrc.org/spa/resources/documents/misc/5tedfg.htm (acceso: 2017). 
se subordinan al gesto de narrar la experiencia (Flawia de Fernández, 2011) ${ }^{16}$ sino también a través de otros signos de oralidad propios del social media. Temporalidades y fronteras se disuelven entre contextos sociales: «los migrantes territoriales», por las necesidades propias de la adaptación e interculturalidad, se reconfiguran como «migrantes digitales» $\mathrm{y}$ «los contenidos mediáticos pueden afectar la formación identitaria simbólica». «Ciudad e internet son espacios de circulación e intercambio y espacios políticos, públicos y privados, en los que la ciudadanía se realiza y se transforma» (Tapia, 2014, p. 98).

La reconstrucción de tales entornos virtuales mediante la lectura textual de sus imágenes (Ardevol y Gómez, 2012, pp. 181-208) permitió calibrar el contacto entre los usuarios y las variables de su recepción. Las autorrepresentaciones de los Wpps y Besf bien serían imágenes de resistencia, conmensurables a los sucesos offline donde campean el vacío legal, la informalidad y valores de supervivencia cambiantes. Al haber sido una movilización pactada - y relativamente exitosa - de inmersión radical de individuos en un ambiente de alto riesgo, sus autorrepresentaciones resaltan el compromiso con la sociedad del guerrero varón, al lado de sus valores y afectos por la patria, las instituciones y la familia. Así, los relatos sustentados en iconos y emblemas de filiación — por ejemplo: el Ejército peruano, la operación militar «libertad para Irak» y el emblema de la CMPS, Triple Canopy Co. (figura 1) - , además de revelar una migración de imaginarios, consolida también las condiciones sociales del sujeto militar o guardia de seguridad subalterno con relación a su hombría, y afianza en forma permanente las condiciones sociales de su virilidad, ya que, su cuerpo es, a la vez, materia prima y capital para ejercer ese rol $^{17}$.

Suponiendo una perspectiva renovada del futuro, su círculo de cotidianidad y el anhelo de retorno al hogar se completaría en la interactividad mediante los registros y diversas ediciones que otros usuarios y agentes mediáticos han retransmitido y resignificado:

16 Ver: Flawia de Fernández, (2011): «A partir de lo ficcional se accede de diferente forma al conocimiento de la realidad, ya que no interesa el documento frío o meramente enunciativo para poner la atención desde la interioridad misma del objeto, en la visión que de él tienen multitud de anónimos personajes, en el rescate de su 'tempo', en la relación de hechos no significativos desde la óptica del poder pero relevantes para el individuo y que devienen en simbólicos. Es una forma de complementar el discurso histórico al ofrecer muchas veces, el reverso de la historia oficial».

17 Sobre estos aspectos, ver: Repensando el machismo latinoamericano. Masculinidades (Fuller, 2012, pp. 123-125). 
El presente enunciativo que abre sus textos revela una crisis a partir de la cual todo el enunciado adquiere el valor de cuestionamientos que propician una nueva lectura del pasado y de sus consecuencias. De esa forma, enunciación $\mathrm{y}$ enunciado, en permanentes toques y confrontaciones, develan al mismo tiempo lo personal-subjetivo y lo histórico-social con un tono en el que fácilmente se advierte el afán de pluralidad discursiva. Es decir, la decodificación es al mismo tiempo estética e ideológica (Flawia de Fernández, 2011).

Figura 1. Iconos y emblemas presentes en los videos de autorrepresentación ${ }^{18}$.
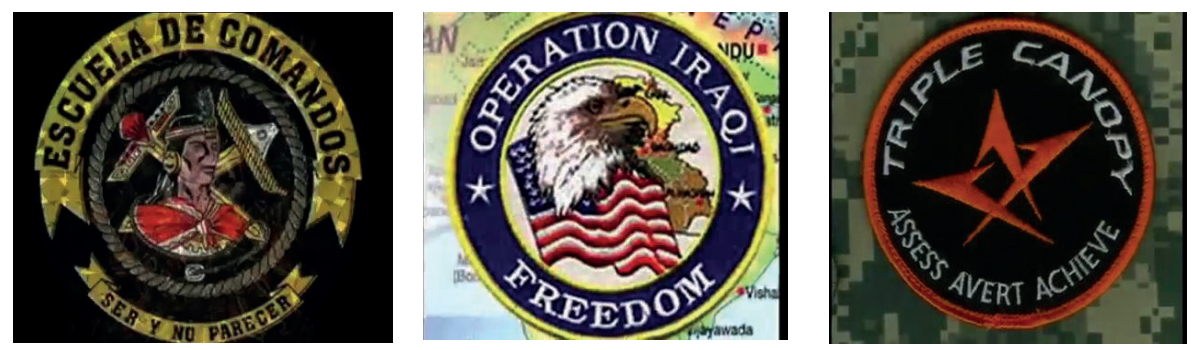

En esta construcción colectiva, la hombría, es decir, la condición de «varón proveedor» (concreto o simbólico) de la economía familiar y nexo con la esfera pública (Fuller, 2012, pp. 123-125) trasciende la oportunidad de trabajo, aprendizaje e internacionalización de la práctica en seguridad. El trabajo digno (libre) en un contexto extranjero pone en valor su ciudadanía por encima de los relegados, $\mathrm{y}$ es entonces cuando el sentido del honor tiñe las autorrepresentaciones como un poderoso argumento de lucha: los Wpps o Besf honran a sus instituciones, a la práctica militar, a su país y a su familia. Una variable importante ha de ser la figura del heroísmo y la narratividad épica. Los Wpps o Besf representan literalmente héroes y embajadores de su cultura en $\operatorname{Irak}^{19}$.

En consecuencia, esta expresión de agencia en una guerra importante se une a un afán de identidad peruana tributable en lo público y lo privado; las autorrepresentaciones conjugan en la misma unidad estética, ideológica y figurativa, tanto al arquetipo de «Rambo», continente «de imágenes del poder masculino, de la inocencia y fuerza americanas» (Kellner, 2011, p. 69), como al «acto

18 Dedicado a todos los Wpps peruanos. Videoclip de autorrepresentación, 2007. http://www. youtube.com/watch?v=PWdJa7zS9Ig

19 Ver el video de autorrepresentación: Mistura peruana en Iraq. https://www.youtube.com/ watch? $=\mathrm{rFhWx}$ Vatuqk (acceso: 2014). 
icónico intrínseco», es decir, aquel de la imagen que extrae su «potentia de la forma» (Bredekamp, 2017, p. 186). De allí el rango iconográfico heterogéneo, pero reminiscente, de una realidad histórica común anquilosada en violencias y estereotipos que se replican por los niveles de hipertextualidad y navegación múltiple, causando la impresión de ser narrativas digitales no estructuradas ${ }^{20}$. En estas, las categorías visuales son transversales e intercambiables por «una enorme multitud de voces que cuentan simultáneamente relatos sobre hechos, acontecimientos, situaciones, sueños y sugerencias, para ser recontados desde una estructura abierta y flexible» (Londoño, 2010, p. 55).

Los elementos de dicho tejido virtual gravitan en torno al imaginario social de la guerra, con énfasis en las escenas de violencia, la maquinaria militar y los entrenamientos: cuerpo masculino en acción, atributos y virilidad, testimonio y retrato. De otro lado, la cultura material abunda en objetos como condecoraciones, emblemas, escudos, lemas, plegarias, símbolos y trofeos. Los rituales de honor, cortejos fúnebres y sometimiento de individuos se suman a la construcción del repertorio visual. A esto se añade la mirada turística sobre el territorio extranjero confrontado y sobre la añoranza del territorio nacional. Tal es el caso del video Dedicado a todos los Wpps peruanos (2007) ${ }^{21}$, presumiblemente realizado por el protagonista, un ex Wpps peruano en Bashora, Irak.

\section{CUOTA DE TRIBUTOS EN YOUTUBE, CUOTA DE RECONOCIMIENTO MASIVO}

La narrativa enfoca una imagen épica de identificaciones con los distintos agentes sociales y los escenarios: la base de operaciones en Bashora, los campos de entrenamiento, los arsenales de guerra, puestos de vigilancia, el campamento y el recinto personal. En las imágenes, los objetos tienen particular importancia: armas, artillería pesada, tanques, pines, uniformes, iconos/emblemas, tarjeta de identificación («W»). Asimismo, las poses de acción (se muestran lesiones de guerra) y otros atributos del combatiente que se resaltan más que nada por el momento histriónico de las tomas. En este video se incluyen: imágenes del vuelo

20 La acepción narrativa digital no estructurada es propia e indica que los actores sociales no son autores de tales narrativas. Esto corresponde a una interpretación antropológica. De otro lado, narrativa digital no lineal se refiere a la condición de interactividad.

21 Dedicado a todos los Wpps peruanos. Videoclip de autorrepresentación, producción amateur, 2007. http://www.youtube.com/watch?v=PWdJa7zS9Ig Video protagonizado por un ex Wpps, 10', Formato: Mp3, 2007, tomado en 2013. 
a Irak y una secuencia de seguimiento al Wpps principal durante su instalación en el recinto, registros de bombardeos y ataques con morteros. La parte introductoria del video muestra elementos gráficos que aluden a escudos o emblemas de carácter corporativo. En uno de ellos se ve la imagen fragmentada de un mapa entre palmeras sobre un sol naciente con predominio del rojo y el amarillo sobre negro, y la yuxtaposición de una banda horizontal multicolor encima de dos espadas cruzadas en «V» (figura 2). En el contorno del círculo se lee: Operation Iraqi Freedom y Veteran, alusivos a la operación de liberación iraquí ${ }^{22}$. El arquetipo de guerrero moderno asociado al veterano estadounidense visibiliza un atributo social clave históricamente legitimado y ahora revalidado para el guardia de seguridad: el dador de justicia. En otro nivel de interpretación, este paradigma de control de la seguridad global se manifiesta en enunciados paternalistas (Golinger, 2016) ${ }^{23}$.

Figura 2. Fotograma del video Dedicado a todos los Wpps peruanos, 2007

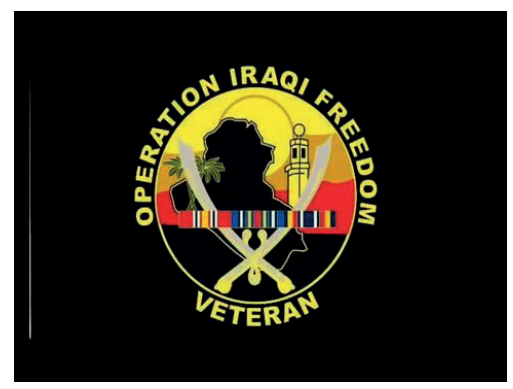

El segundo icono emblemático contiene la palabra mercenario, coronando un personaje cadavérico de mirada siniestra con boina verde (figura 3.a) ${ }^{24}$. La cabeza está atravesada por una espada, entre la parte superior del cráneo y los dientes; a la vez la traspasan dos flechas entrecruzadas. El personaje tiene como fondo orna-

22 Nótese en este emblema, el valor del prototipo americano en la categoría Veteran, a pesar de que en Estados Unidos constituye una problemática social relevante, especialmente, desde la guerra de Vietnam en adelante: el Golfo, batalla del Mogadiskio, guerra de Irak, etcétera. Por otro lado, es uno de los países que concentra el mayor número de veteranos de guerra en el mundo.

23 Sobre los discursos de intervencionismo, ver: ¿Cómo justifica EE.UU. una guerra? Eva Golinger, Telesur. entrevista a la abogada, enero, 2016. https://www.telesurtv.net/news/ Como-justifica-EE.UU.-una-guerra-20160127-0076.html (acceso: octubre de 2017).

24 Los «boinas verdes» fueron originariamente fuerzas especiales del ejército de Estados Unidos (desde 1952), grupos reducidos con rango de sargento o superior (cuerpo de élite). Hoy son «modelo» en otros contextos. En el Perú, la escuela de comandos la utiliza como parte de su indumentaria (hoy en negro). 
mental orlas de fuego. Se leen otros dos textos de contorno: De oppre so liber y Operation Basora ${ }^{25}$. Este es semejante a un icono de los Boinas Verdes, que en vez de mercenario, dice Special Forces (figura 3.b). La réplica del modelo militar en diferentes contextos reajusta también su iconicidad, incluyendo, sobre todo, leyendas que refieren al contexto geográfico, a las fuerzas protagonistas o al conflicto ${ }^{26}$.

\section{Figura 3. Fotograma del video Dedicado a todos los Wpps peruanos (2007) e icono referencial en otro contexto}
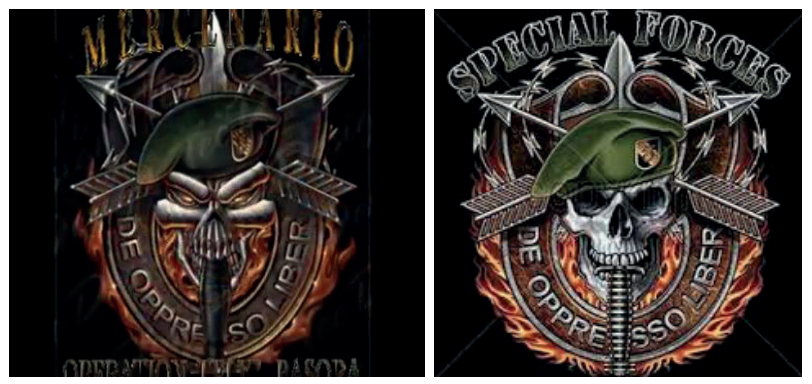

a. Icono del video de los guardias de seguridad. b. Icono de los boinas verdes.

En el video mencionado, se incluye un icono relativo a la escuela de comandos del Perú. El lema «Ser y no parecer» se consigna a la vez como una suerte de estribillo de orgullo patrio en los foros y ratifica para los migrantes a Irak una identidad militar que demanda reconocimiento y ciudadanía, concepto último subalterno de lo primero en la tradición totalitaria del país ${ }^{27}$.

Texto en latín: liberar de la opresión / operación Basora.

26 Los grados de iconicidad sobre el modelo descrito trascienden la cultura material y popular desde vestuario, indumentaria y objetos varios. Su máximo estereotipo es el personaje Rambo (80-90), también en videojuegos. Ver en: http://www.ciao.es/Rambo_Xbox_360_ Opinion_2339101a. Para apreciar múltiples variantes de esta iconografía, ver: $\bar{h}$ ttps://www. google.com.pe/search?q=icono+original + de + los + boinas + verdes + americanos\&safe $=$ active \& $t$ bm=isch\&tbs=rimg:CQmVfPQEXOPzIjivzfWSMPIHViun1i-QWUzYb3OxvPCJPDeT2X0kbeMWQasI7dFNkwsNB0N6DHQQfcDcFQxcKk_1hyioSCa_1N9ZIw8gdWEd6UVPYeMFb kKhIJK6fWL5BZTNgR8WtyyAXDdDoqEglvc7G88Ik8NxEz1JTQWbhOlCoSCZPZfSR t4xZBEbIfKk0PIvNFKhIJqwjt0U2TCw0R47aqmvVTGIoqEgkHQ3oMdBB9wBHNQW7KcrAfLioSCdwVDFwqT-HKEdj5iPHgEla2\&tbo=u\&sa=X\&ved=0ahUKEwiylMS9t4XXAh VHj5AKHWYfDxEQ9C8IHw\&biw=1600\&bih=794\&dpr=1 (acceso: octubre de 2017). En el contexto peruano, un sitio web del comando Aquiles utiliza una derivación del icono de los boinas verdes donde aparece también un lema transcultural de origen espartano, vencer $o$ morir, y de otro lado, la frase dream team killer's. Ver: http://daymarkperu.galeon.com/ blog de un miembro de la Escuela de Comandos del Perú (acceso: 2015 y 2017).

27 Ver en https://www.facebook.com/VeteranosPeru/timeline, veteranosperu.com: https://www. facebook.com/groups/96717991756/ problemáticas económicas y legislativas de las FFAA 
Figura 4. Fotograma del video Dedicado a todos los Wpps peruanos (2007). Emblema de una escuela de comando del Ejército peruano

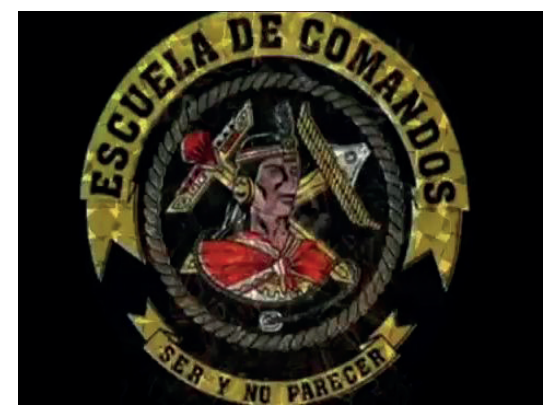

En la descripción heráldica del blog citado, los puñales representan un arma tradicional de ataque sorpresa característica de los comandos (figuras 2, 3.a, 4) ${ }^{28}$. No obstante, lo que llama la atención de estas reiteraciones es la asociación de comando con mercenario. En el siguiente ejemplo, los puñales atravesados del escudo de la escuela de comandos mutan en un elemento similar semejante a las dos cimitarras cruzadas del emblema nacional de Arabia Saudita, las cuales también figuran debajo de una palmera ${ }^{29}$.

\section{LA AMENAZA DE UN MERCENARISMO PERUANO DETRÁS DE LA ADOPCIÓN DE MODELOS TRANSNACIONALES POR LA PRÁCTICA MILITAR CUANDO LAECONOMÍADEMERCADODESBORDASUDOMINIO}

Como ha sido explicado anteriormente, la visualidad de este hecho agrupa problemáticas diversas: trabajo, educación, género, ciudadanía, gobernabilidad, políticas públicas, salud, economía, etcétera. Y, aunque el presente artículo subraye aspectos generales y pretenda detenerse en lo concerniente a la configuración de las autorrepresentaciones, resulta necesario referir que los nuevos paradigmas

o de la PNP; otros sites, «Veteranos del conflicto del Atlántico Sur (ZDC) (Guerra de las Malvinas)», constituyen grupos públicos y se debaten problemáticas similares. Ver: https:// www.facebook.com/VeteranosPeru/timeline veteranosperu.com. También, ver: https://www. facebook.com/groups/96717991756/https://www.facebook.com/VeteranosPeru/timeline veteranosperu.com. También, ver: https://www.facebook.com/groups/96717991756/

28 La espada es un símbolo de honor, y las espadas curvas con ciertas variantes morfológicas y de posición de cruce aparecen en variados contextos.

29 En Bagdad hay un monumento, Las manos de la victoria (Irak/Irán), de grandes espadas cruzadas como arcos de triunfo. 
éticos frente a la seguridad internacional admiten el mercenarismo contemporáneo, y en seguida, la violencia (Owens, 2008). Es de notarse que la producción y consumo de estos videos en internet, aun partiendo de actores locales, es signo de un cambio trasnacional de la «identidad» y la «sociedad civil» (Hopenhayn, 2005, citado en Mato, 2005):

Esta reconfiguración conceptual produce a su vez una reorientación de las prácticas de algunos actores, fortaleciendo las posiciones de los actores globales y creando redes bilaterales con actores locales, fomentando su participación en eventos y redes de trabajo. Frente a este contexto, Mato se interroga acerca del papel que juegan las (nuevas) representaciones sociales en la formulación de los programas de acción de ciertos actores (Mato, 2005).

El documental periodístico de Fernando Lucena America's 33 dollar mercenaries (2013), al abordar este caso, desliza un compendio crítico de conflictos ligados a la privatización de la guerra, donde se debate la desagregación del sujeto libre y la vulneración de sus derechos. Entre otras declaraciones, se aduce que los peruanos actuaron en libertad por un puesto defensivo y se señala «un gap discursivo» en los contratos al nominar a los sujetos como Guards (posición neutra). De facto, se les exculpa de ser combatants (Lucena, 2013). Se presume que el marco jurídico de esos contratos privados no explicitaba lo suficiente el sentido mutuo sobre los derechos individuales en un contexto de alto riesgo, ya que varios trabajadores padecieron daños físicos irreversibles ${ }^{30}$. En contraposición, el contrato de trabajo del régimen público es diferente. Este se estipula en función de una colectividad, donde los derechos y obligaciones tienen una base de sostenibilidad social protegida por una estructura legal mayor. Aunque acá no aplicase, la combinación de agentes públicos y privados es lo que llama la atención ${ }^{31}$.

No obstante, entre los testimonios se priorizaron detalles que contrastan todos estos aspectos críticos, dando pase a lo anecdótico. Aun así, los guardias entrevistados validaron la producción de Lucena en contraposición a los

30 Se reportaría la muerte de un trabajador. Ver: Noticia local, muerte de peruano, 24 HORAS, noticiero TV. http://www.youtube.com/watch?v=1ysyLle2kgo

Para profundizar sobre los regímenes laborales y su evolución local, donde coexistieron «modos mixtos por la superposición de valores modernos», que aportan a la comprensión de los debates legales de las relaciones contractuales de este tipo de trabajador, ver: Themis, vol. 20, Paradojas de la modernización: el contrato de enganche, Fernando de Trazegnies, p. 13. http://revistas.pucp.edu.pe/index.php/themis/article/view/10892/11397

31 L'avenir de la codification en France et en Amérique Latine. Ver:_http://www.senat.fr/colloques/colloque_codification/colloque_codification11.html 
videos de autorrepresentación de los mismos actores, probablemente por una apelación a la forma especializada frente a la forma amateur, como también por las restricciones de registro, uso de celulares, participación en redes sociales y como precaución ante la posibilidad de entablar juicios con las aseguradoras por supuestas coberturas irresueltas.

Algunos registros anónimos insertos en estos videos también fueron utilizados por los medios, ya que por tratarse de tomas subjetivas de un evento real poseen un valor mediático potente. Lejos de constituir una evidencia audiovisual de sus experiencias, son fracciones históricas de una narrativa global sobre la guerra. En ese sentido, aparte del video analizado, estos registros anónimos de la estancia en Irak son reeditados con otros archivos personales o elementos de cultura popular, destacándose también el referente religioso y los esencialismos de la naturaleza. De esta manera, fuera de cánones muy elaborados, lo que prima son los pastiches colectivos que pueden coadyuvar a develar a un tipo de actor social tradicionalmente cuestionado - el mercenario- pero reconocido y naturalizado desde la práctica militar y desde la mirada social que identifica en lo militar un mal necesario.

\section{CONCLUSIONES}

La frágil gobernabilidad de los estados deja ser al sistema de libre mercado, el cual regula sus propias deficiencias y las capitaliza de forma conveniente ${ }^{32}$. Los guardias de seguridad peruanos en Irak ejercieron su libertad individual gracias a la globalización y la masculinización de su práctica en conflictos internacionales. El orden social contribuyó con esta libertad de acción a cambio de que este sujeto libre fuera también un sujeto políticamente neutro, integrado a los parámetros de solvencia de un sistema homogéneo. Por ello, en el plano mediático la dialéctica del caso desembocó en un círculo vicioso y especulativo, apostando más a un posible impacto internacional a través de estos individuos y sus «economías personales» que a la visibilización de un hecho que acarreaba debates necesa-

32 Seyla Benhabid, en El derecho de los otros, destaca para el individuo libre, moderno y con derechos un campo de interacciones sociales regido por la conveniencia del «cosmopolitismo», «las ambivalencias de la ciudadanía desagregada», de cómo las democracias en los estadosnación de la modernidad y sus estatutos construyen y administran la identidad ciudadana sobre la base del contrato económico, vale decir, la venta del trabajo asalariado sostenida por los países capitalistas para asegurar un corpus ciudadano homogéneo y territorialmente autosuficiente. 
rios sobre las ciudadanías. Sin embargo, queda claro para el estudio que a este tipo de migrante no se le puede ni esencializar ni categorizar fuera de procesos sociohistóricos específicos y de políticas públicas que legitiman el rumbo de sus identidades, pues estas nominaciones influyen en «las representaciones sociales y en la vida misma de las personas que cotidianamente experimentan la vida como migrantes» (Bela Feldman, 2011, p. 17).

Las supuestas arbitrariedades padecidas por los trabajadores en el atraso de sus pagos, compensaciones, restricciones de consumo, los problemas del idioma, el control militar, etcétera, a la larga se tradujeron en una voluntad de negociación y ventaja de ambas partes, utilizándose canales de persuasión sofisticados y creativos en términos de adaptación social. No obstante, según los testimonios, la proeza les significó a los ex guardias de seguridad una reinserción social difícil y casi estigmatizada, pero en muchos casos fructífera y con nuevos arraigos. Textualmente: «Irak les dejó la sensación de haber ganado y perdido todo a la vez». Y este clamor épico y nostálgico de nacionalismos se formalizaría en la transmisión online de las experiencias y el germen de una ciudadanía plural.

Y así como la paradoja citada anticipaba un horizonte hipermedial ${ }^{33}$ nada fácil de aprehender, donde no hay certidumbre cuantitativa ni imágenes labradas con los mismos objetivos, se reforzó el concepto de que las mediaciones e iconicidades predeterminaban estas identidades múltiples.

Por esta razón, todos los elementos mediales señalados constituyen un testimonio directo de este hecho social, equiparable al contacto interpersonal fuera de línea. Tanto la migración estacional de personas como la migración icónica devienen lo mismo. La data percibida en simultaneidad nos permite apreciar $a d$ infinitum realidades superpuestas y ramificadas, como también procesos circulares o concéntricos: una problemática dentro de otra.

\section{REFERENCIAS BIBLIOGRÁFICAS}

Abrisketa, Joana (2007). Blackwater: Los mercenarios y el Derecho internacional. Fundación para las Relaciones Internacionales y el Diálogo Exterior (FRIDE). Archivo PDF. En cátedra Von Humboldt, Universidad de Bogotá. Ver: http:// fride.org/descarga/COM_blackwater_ESP_sep07.pdf

Ansion, Juan (2007). La interculturalidad y los desafíos de una nueva forma de ciudadanía. En Juan Ansion y Fidel Tubino (eds.), Santiago Alfaro, María Elena

33 Op. cit. Conjunto de textos e imágenes mediales, p. 15. 
González, Luis Mujica, Rita Segato y Marco Villasante: Educar en ciudadanía intercultural (pp. 37-61). Lima: Fondo Editorial PUCP.

Ardevol, Elisenda (2014). Visualidades y materialidades de lo digital: caminos desde la antropología. Anthropologica, XXXII(33), 11-38, 115.

Ardevol, Elisenda y Edgar Gómez-Cruz (2012). Cuerpo privado, imagen pública: el autorretrato en la práctica de la fotografía digital. Revista de Dialectología y Tradiciones Populares, LXVII(1), 181-208, enero-junio. https://doi.org/10.3989/ rdtp. 2012.07

Ardevol, Elisenda, Rocío Trinidad, Deborah Lanzeni, Marián Moya y Maximiliano Rua (2012). Seminario sobre diversidad cultural y nuevas tecnologías. Facultad de Ciencias Sociales de la PUCP.

Arendt, Hanna (2005). Sobre la violencia. Madrid: Alianza Editorial.

Baudillard, Jean (1991). La guerra del Golfo no ha tenido lugar. Barcelona: Anagrama.

Baudillard, Jean (2005). War Porn. International Journal of Braudillard Studies, 2(1), Number 1 (January). En URL http://www.ubishops.ca/baudrillardstudies/vol2_1/ taylor.htm Revisado el 13/07/11)

Bela-Feldman Blanco, Liliana Rivera Sánchez, Carolina Stefoni y Marta Inés Villa Martínez (comp.) (2011). La construcción social del sujeto migrante en América Latina. Quito: Flacso.

Benhabid, Seyla (2004). Los derechos de los otros. Extranjeros, residentes y ciudadanos. Barcelona: Gedisa.

Bredekamp, Hosrst (2017). Teoría del acto icónico. Madrid: Akal.

Cueto, Nogueras, Carlos García y Miguel Guindo (2008). La privatización de los conflictos: Las compañías militares privadas de seguridad. En Carlos Navajas Zubeldía y Diego Iturriaga Barco (eds.), Crisis, dictaduras, democracia (pp. 389-394). Actas del I Congreso Internacional de Historia de Nuestro Tiempo. Logroño: Universidad de La Rioja.

De Trazegnies Granda, Fernando (1991). Paradojas de la modernización: el contrato del enganche. Themis, 20, 13-19.

Debord, Guy (1976). La sociedad del espectáculo. Madrid: Miguel Castellote.

Delgado Hinostroza, Pedro Pablo (2013). Apátridas, refugiados y migrantes, el derecho a la libre circulación. Lima: Fondo de Cultura Económica.

Echeverri Ortiz, Alberto José (2011). Narrativas digitales: el arte de la narración en la cibercultura. Tesis de grado en estudios literarios, Universidad Javeriana. https://repository.javeriana.edu.co/bitstream/handle/10554/6485/tesis2 25 . pdf? sequence $=1 \&$ is Allowed $=\mathrm{y}$ 
Flawia de Fernández, Nilda María (2011). Relación entre la ficción y la historia. Alicante: Biblioteca Virtual Miguel de Cervantes. http://www.cervantesvirtual.com/ obra/relacion-entre-la-ficcion-y-la-historia/

Foucault, Michel (2000). Defender la sociedad. Curso en College de France (19751976). México: Fondo de Cultura Económica.

Foucault, Michel (2002). Panoptismo. En Vigilar y castigar. Nacimiento de la prisión (pp. 192-224). Buenos Aires: Siglo XXI (PDF). http://www.fmmeducacion.com. ar/Bibliotecadigital/Foucault_VigilaryCastigar.pdf

Fuller, Norma (2012) Repensando el machismo latinoamericano. Masculinities and Social Change, 1(2), 114-133. https://doi.org/10.4471/MCS.2012.08

Godelier, Maurice (1974). Antropología y economía. Barcelona: Anagrama. Recuperado de https://www.ddooss.org/libros/maurice_godelier.pdf

Gómez Castro, Daniel, El mercenario en el mundo griego a la luz de los estudios contemporáneos: reflexión teórica y nuevas tesis. Universitat Autónoma de Barcelona. Recuperado de http://institucional.us.es/revistas/habis/41/art_7.pdf

$\mathrm{Gu}$, Jie (2014). Participating in youtubing practice: towards a practice perspective to understand user participation motivations. School of Television. Faculty of Journalism and Communication, Communication Univeristy of China. Recuperado de http://www.media-anthropology.net/file/gu_youtubing.pdf

Gutiérrez, Kevin Roberto (2012). El hoplita griego y la guerra en la Grecia Antigua. Bogotá: Universidad Nacional de Colombia, Facultad de Ciencias Humanas, Maestría en Historia.

Habermas, Jurgen (2009). El occidente escindido. Madrid: Trotta. Recuperado de https://scholar.google.com/scholar?q=related:alnItRhHOnQJ:scholar.google. com $/ \&$ scioq $=\& h l=$ es\&as_sdt $=0,5$

Jenkins, Henry (2008). Convergence Culture. La cultura de la convergencia de los medios de comunicación. Barcelona: Paidós.

Kymlicka, Will (1996). Las políticas del multiculturalismo. En Ciudadanía multicultural: una teoría liberal de los derechos de las minorías. Cap. 2 (pp. 25-55). Barcelona: Paidós.

L'Avenir de la codification en France et en Amérique Latine (2014). En Un site au service de citoyens. Recuperado de http://www.senat.fr/colloques/colloque codification/colloque_codification11.html

Kellner, Douglas (ed.), Amaya Bozal (trad). (2011). Estudios culturales, identidad y política entre la modernidad y la posmodernidad. Madrid: Ediciones Akal.

Laborie Iglesias, Mario, (2012). La privatización de la seguridad, las empresas militares y de seguridad privadas en el entorno estratégico actual. Madrid: Instituto 
Español de Estudios Estratégicos. Recuperado de http://www.ieee.es/Galerias/ fichero/OtrasPublicaciones/Nacional/La_Privatizacion_de_la_Seguridad_T152090212_MarioLaborie.pdf

Landow, George P. (1995). Hipertexto: la convergencia de la teoría crítica, contemporánea y la tecnología. Barcelona: Paidós. Recuperado de http://www.unsj. edu.ar/unsjVirtual/comunicacion/seminarionuevastecnologias/wp-content/ uploads/2017/04/2011_landow_hipertexto_cap_11.pdf

Londoño Palacio, Olga Lucía (2010). Las narrativas desde la hipertextualidad. Características, modelo y metodología a partir de la inteligencia sintiente. Revista de investigaciones UNAD, 9(1). Recuperado de https://academia.unad.edu. co/images/investigacion/hemeroteca/revistainvestigaciones/volumen9numero1_2010/4\%20las\%20narrativas\%20desde\%201a\%20hipertextualidad.pdf

López, Gilberto y Rivas (2008). Antropología, contrainsurgencia y terrorismo global. Contexto Latinoamericano, 7. Enero/Marzo. Recuperado de http://www.tlaxaca. es/pp.asp?reference $=5441 \& \lg =\mathrm{de}$

Maccormick, Neil (2010). Argumentación e interpretación en el derecho. DOXA, Cuadernos de Filosofía del Derecho, 33, 65-78 https://doi.org/10.14198/ DOXA2010.33.04

Malgesini, Graciela (1998). Cruzando fronteras, Migraciones en el Sistema Mundial. Barcelona: Fundación Hogar del Empleado.

Mato, Daniel (comp.) (2005). Cultura, política y sociedad. Perspectivas latinoamericanas, (antología). Colección Grupos de Trabajo. Buenos Aires: CLACSO.

Owen, Patricia (2008). Distinctions, distinctions: 'public' and 'private' forcé. International Affaires, 84, 5. The Author(s). Journal Compilation. Blackwell Publishing Ltd. / The Royal Institute of International Affairs. https://doi.org/10.1111/j.14682346.2008.00750.x

Paerregard, Karsten (2013). Peruanos en el mundo, una etnografía de la migración. Lima: Fondo Editorial de la PUCP.

Palou-Loverdos, J. (dir.) y L. Armendáriz (autor) (2011). The Privatization of Warfare, Violence and Private Military \& Security Companies: A factual and legal approach to human rights abuses by PMSC in Iraq. Recuperado de http://psm. du.edu/media/documents/reports_and_stats/ngo_reports/ictc-pmsc_private_ security_legal-approach_abuse_iraq.pdf

Pareck, Bhicku (2005). Repensando el multiculturalismo - diversidad cultural y teoría política. Introducción (pp. 13-15). Madrid: Istmo.

Postill John (2014-2015). Freedom technologist and the future of global justice. http:// johnpostill.com/category/freedom-technologists-series/ 
Quijano, Aníbal (2004). Colonialidad del poder, eurocentrismo y América Latina. En: Ramón Pajuelo y Pablo Sandoval (comps.), Globalización y diversidad cultural. Una mirada desde América Latina (pp. 228-281). Lima: IEP.

Ranciére, Jacques (2006). Política, identificación, subjetivación y «la causa del otro». En: Ranciere, política, policía, democracia. Santiago de Chile: LOM.

Rivera, Alejo Julio (2013). La militarización del espacio, un desafio a la seguridad internacional y un reto para el Derecho Internacional. Ensayo. Universidad Complutense de Madrid.

Rosaldo, Renato (1991). Dilemas de un análisis procesual. En: Cultura y verdad. México: Grijalbo.

Said, Edward (1990). Orientalismo. Madrid: Libertarias.

Said, Edward (1997). Covering Islam: How the Media and the Experts Determine How We See the Rest of the World. Edición revisada. Nueva York: Vintage Books.

Sen, Amartya (2007). Multiculturalismo y libertad. En Identidad y violencia: la ilusión del destino (pp. 201-225). Buenos Aires: Katz.

Tapia Fernández, Joselito (2014). Argentinos y peruanos en la ciudad de México, 19702009. ¿Configuración de una ciudadanía transnacional digital? Ánfora, 21(36), 91-123. Universidad Autónoma de Manizales. Recuperado el 29 de septiembre de 2018, de http://www.redalyc.org/articulo.oa?id=357833887004

Taylor, Charles (1993). El multiculturalismo y la política de reconocimiento. México DF: Fondo de Cultura Económica.

Toreiro, Casimiro y Josétxo Cerdán (2005). Diálogo entre el documental y vanguardia en clave autobiográfica. Madrid: Cátedra.

\section{Videografia / Sitios web}

Blog de Carlos A. Quiroz

http://peruanista.blogspot.com/2007/05/soldados-peruanos-en-irak-y-afganistan.html (acceso: 2014).

Dance party in Irak. Video https://www.youtube.com/watch?v=UW1 toLy_FMQ (acceso: 2015).

Dedicado a todos los Wpps peruanos. Video (peruanos en Iraq Basora. Flv) https://www.youtube.com/watch?v=CYKAlegCQUA (acceso: 2014).

Día de relajo en la piscina. Video

https://www.youtube.com/watch?v=keah-lRiZwU (acceso: 2014). 
Difunden video de caída de avión de carga en Afganistán http://elcomercio.pe/actualidad/1570990/noticia-difunden-video-supuestacaida-avion-carga-afganistan (acceso: 2015).

En el Ejército se entrenaron peruanos que fueron a Irak. La República. http://larepublica. pe/politica/293244-en-el-ejercito-se-entrenaron-peruanos-que-fueron-a-irak (acceso: noviembre de 2017).

Entrevista de Zenaida Solís a un Wwps 122 http://www.webislam.com/ noticias/45671usan_a_peruanos_como_mercenarios_en_irak.html (acceso: 2014).

Entrevista soldado hispano en Irak 121 http://www.youtube.com/watch?v=cEQ5cVzBJsg (acceso: 2014).

Este ataque cruel y sin sentido no disuadirá a Estados Unidos de llevar a cabo sus objetivos de trabajar con el Gobierno iraquíy el pueblo para construir un futuro democrático http://elcomercio.pe/mundo/612235/noticia-peruano-murio-alcanzado-coheteiraq (acceso: 2014).

Foro social

http://www.taringa.net/posts/videos/12397395/Peruanos-son-Atacados-conMorteros-en-Irak-18.html (acceso: 2014).

http://peru21.pe/noticia/41366/solicitan-que-tres-ministros-declaren-sobre-situacionperuanos-irak (acceso: 2014).

http://peru21.pe/noticia/83825/eeuu-determinar-su-responsabilidad-vida-peruanos-irak (acceso: 2014).

http://peru21.pe/noticia/84564/mercenarios-peruanos-irak-narran-vida-este-pais-sinmujer-cerveza-ni-fiestas (acceso: 2014).

https://www.academia.edu/6796052/Ensayo_La_militarizaci\%C3\%B3n_del_Espacio._Un_desaf\%C3\%ADo_a_la_seguridad_internacional_y_un_reto_para_el_ Derecho_Internacional

Lanzan un rifle cristiano en EEUU para evitar que caiga en manos de terroristas https://es-us.noticias.yahoo.com/lanzan-rifle-cristiano-eeuu-evitar-caigamanos-terroristas-172235218.html (acceso: 2014).

Las compañias militares privadas. Documental http://www.youtube.com/watch?v=YUPkBaIS3Aw (acceso: 2014).

Ley del Migrante Retornado

http://www.andina.com.pe/espanol/noticia-gobierno-y-sociedad-civil-avanzanreglamento-ley-del-migrante-retornado-458687.aspx (acceso: 2014).

Lucena, Fernando (2013). America 33 dollar's mercenaries. Documental para la Presstv. http://www.fernandolucenafilms.co.uk/productions.php (acceso: 2014). 
Mistura peruana en Iraq. Video https:/www.youtube.com/watch?v=rFhWxVatuqk (acceso: 2014).

Noticia local. Muerte de peruano. 24 HORAS, noticiero TV http://www.youtube.com/watch?v=1ysyLle2kgo (acceso: 2014).

ONU reconoce que quien ha usado armas químicas en Siria son los mercenarios y no el gobierno http://www.insurgente.org (acceso: 2014).

ONU reconoce que quien ha usado armas químicas en Siria son los mercenarios y no el gobierno http://www.insurgente.org (acceso: 2015).

PERÚ: Mercenarios para Iraq con ayuda del ejército, Inter press-service, agencia de noticias (acceso: noviembre de 2017).

Peruano cantando en Irak. Video https://www.youtube.com/watch?v=JPIjFgm4puc (acceso: 2015).

Peruanos en Iraq celebrando fiestas patrias y mistura 2012. Video https://www.youtube.com/watch?v=PWdJa7zS9Ig 120 (acceso: 2014).

Registro de peruanos con pollada en Irak. Video http://www.youtube.com/watch?v=CYKAlegCQUA (acceso: 2014).

Réplica de privatizaciones en las fuerzas del orden locales http://www.rpp.com.pe/2011-03-31-vigilantes-privados-apoyaran-a-la-policiaen-seguridad-ciudadana-noticia_350774.html (acceso: 2014).

Reporte noticiario sobre la Embajada de Irak por TELESUR http://www.youtube.com/watch?v=4DO5dSrRXdw (acceso: 2014). 